\title{
Effects of naringin on the expression of miR-19b and cell apoptosis in human hepatocellular carcinoma
}

\author{
DAFEI XIE ${ }^{1}$, PEIWEN YUAN ${ }^{2}$, DONG WANG ${ }^{1}$, HUA JIN $^{1}$ and HUI CHEN ${ }^{1}$ \\ Departments of ${ }^{1}$ General Surgery and ${ }^{2}$ Intensive Care Unit, Zhejiang Hospital, Hangzhou, Zhejiang 310013, P.R. China
}

Received January 30, 2017; Accepted May 19, 2017

DOI: $10.3892 / \mathrm{ol} .2017 .6278$

\begin{abstract}
The effects of naringin on the expression of miR-19b and cell apoptosis were investigated in the human hepatocellular carcinoma cell line HepG2. HepG2 cells were treated with varied concentrations of naringin. The effects of naringin on the proliferation of HepG2 cells were observed by an MTT assay, morphological changes of cells were observed by an inverted microscope, cell apoptosis was detected by DAPI staining, miR-19b mRNA levels were determined with RT-PCR, and the expression of Bax and Bcl-2 proteins was examined by western blot assay. MTT results showed that naringin significantly inhibited the proliferation of HepG2 cells. Apoptotic HepG2 cells showed obvious changes in morphology under inverted microscope. DAPI staining suggested that naringin could induce cell shrinkage and nuclear chromatin condensation. RT-PCR results showed that naringin could upregulate the expression of miR-19b mRNA. Finally, western blot suggested that naringin upregulated the expression of Bax protein, but downregulated the expression of Bcl-2 protein. In conclusion, naringin can upregulate the expression of miR-19b mRNA and induce HepG2 cell apoptosis. In addition, it can also upregulate the expression of Bax protein and downregulate the expression of $\mathrm{Bcl}-2$ protein during the process of apoptosis.
\end{abstract}

\section{Introduction}

Liver cancer is the fifth most prevalent type of malignant tumor in the world and its incidence has been increasing to its current rate of 50 out of 100,000 people. Liver cancer is also the third leading cause of cancer-related death among malignant tumors (1). By sex, it has become the second and the sixth leading cause of cancer-related death in men and women,

Correspondence to: Dr Dafei Xie, Department of General Surgery, Zhejiang Hospital, 12 Lingyin Road, Xihu, Hangzhou, Zhejiang 310013, P.R. China

E-mail: x6d54o@163.com

Key words: naringin, human hepatocellular carcinoma cell line HepG2, apoptosis, Bax, Bcl-2, miR-19b respectively (2). At present, the main clinical treatment of liver cancer is surgery, but the early clinical symptoms of liver cancer are not obvious and are often overlooked; moreover, when patients have clinical symptoms, such as weight loss, jaundice, abdominal mass and even liver pain, most of them are already in the advanced or terminal stage. Therefore, at present, only $10 \%$ of patients have a favourable probability for complete resection of the liver cancer. Although another $90 \%$ of patients are treated with radiotherapy, chemotherapy, radiofrequency ablation, and other intensive treatments, it is difficult to achieve expected clinical results due to low efficacy and high rates of side effects. Therefore, the treatment of liver cancer is still in an abysmal state due to the absence of effective treatment options $(3,4)$.

Traditional Chinese medicine has many advantages and the active ingredients of its herbs often have properties that impart high efficacy and low toxicity. Scientists worldwide have been giving increasing attention to Chinese herbal medicines due to their irreplaceable advantages. In recent years, with the study of anti-carcinogenic mechanisms of Chinese herbal medicine, more active ingredients have been extracted. Naringin belongs to a family of natural flavonoids and is derived from Rutaceae Citrus Pomelo. Studies have shown that naringin not only has anti-viral effects, but can also support cancer prevention (5). In addition, Birt et al (6), further demonstrated that flavonoids could induce apoptosis and enhance tumor suppressor gene expression, thereby inhibiting tumor cells.

MicroRNA (miRNA) is a single-stranded RNA with a molecular chain length of 22 nucleotides and does not encode for a protein. miRNA can regulate post-transcriptional protein expression via interaction with the 3'UTR region of the target gene mRNA (7). miRNA-19b is one of the major members of the miRNA-17-92 family (8). It has been found that miR-19b is highly expressed in breast, cervical, colon and pancreatic carcinomas and participates in the apoptosis of tumor cells $(9,10)$.

While the relationship between the mechanisms of action of naringin and miRNAs had not yet been reported, the results of our previous study suggested that naringin could increase the expression of miR-19b in HepG2 cells. Therefore, this study aimed to investigate the potential effects of naringin on the proliferation of HepG2 cells and to compare the expression of miR-19b before and after naringin treatment. We also sought to explore the possible mechanisms of naringin in the 
process of apoptosis, thereby laying a scientific foundation for the treatment of hepatocellular carcinoma with naringin.

\section{Materials and methods}

Materials and reagents. Naringin, MTT assay kit (Sigma, St. Louis, MO, USA), human hepatocellular carcinoma cell line HepG2 (Cell Bank of Chinese Academy of Sciences, Shanghai, China), DMEM (Gibco Life Technologies, Carlsbad, CA, USA), RNA extraction kit, reverse transcriptase kit, RT-PCR kit (Invitrogen Life Technologies, Carlsbad, CA, USA), BCA protein quantification kit, cell lysis buffer (Biyuntian Biotechnology Research Institute, Nantong, China) and primer synthesis materials (Takara Bio, Dalian, China) were all sourced for this study.

Cell culture. HepG2 cells were cultured at $37^{\circ} \mathrm{C}$ in a $5 \% \mathrm{CO}_{2}$ incubator until reaching $85 \%$ confluence, then were digested with trypsin and the cell suspension was diluted with DMEM containing $10 \%$ fetal bovine serum until the cell concentration was adjusted to $2 \times 10^{8} / 1$. Cells were then counted and seeded in culture plates for the following experiments.

Determination of cell proliferation inhibition rate. Cell proliferation was measured by MTT assay after the cells were treated with naringin. The cells were seeded into 96 -well plates at a concentration of $1 \times 10^{5} / \mathrm{ml}$, with each well containing $100 \mu \mathrm{l}$. After $24 \mathrm{~h}$, naringin was added until final concentrations reached 10, 20 and $40 \mu \mathrm{M}$, respectively. Each concentration was repeated for 5 wells and the experiment was repeated 6 times, while the control group was not treated with naringin. The cells were incubated for 24,48 and $72 \mathrm{~h}$ at $37^{\circ} \mathrm{C}$ in a $5 \%$ $\mathrm{CO}_{2}$ incubator and then the cell culture medium containing naringin was changed. A total of $10 \mu \mathrm{l}$ MTT was added to each well until a final concentration of $5 \mathrm{mg} / \mathrm{ml}$ was obtained. After $4 \mathrm{~h}$, the optical density (OD) at $570 \mathrm{~nm}$ was measured by a microplate reader. The inhibition rate was calculated according to the following formula: inhibition rate $(\%)=(\mathrm{OD}$ value of normal control group - OD value of experimental group/OD value of normal control group) x $100 \%$.

Morphological observation. Cells were treated with 10, 20 or $40 \mu \mathrm{M}$ naringin for $24 \mathrm{~h}$, respectively, and the morphological changes were observed and recorded with an inverted microscope (Nikon, Tokyo, Japan).

DAPI staining. Cells were seeded in 6-well plates at a density of $10^{4}$ cells/well. After $24 \mathrm{~h}$, the supernatant was aspirated and cells were cultured in medium containing 10,20 or $40 \mu \mathrm{M}$ naringin for another $24 \mathrm{~h}$, then washed with precooled PBS 3 times. DAPI solution $(1 \mu \mathrm{g} / \mathrm{ml})$ was added to each well and cells were incubated in a $37{ }^{\circ} \mathrm{C}$ incubator for $5 \mathrm{~min}$ and washed again with precooled PBS. Cells were then observed and photographed using a fluorescence microscope in the dark (Nikon).

RT-PCR detection. Cells were seeded in 6-well plates at a density of $10^{4}$ cells/well. After $24 \mathrm{~h}$, the supernatant was aspirated and cells were cultured in medium containing 10, 20 or $40 \mu \mathrm{M}$ naringin for another $24 \mathrm{~h}$. The cells were then collected and total RNA was extracted according to the instructions of the RNA extraction kit. Total RNA concentration and purity (A260/A280 >1.8 indicating pure RNA) were determined by UV-Vis spectrophotometer (Hitachi, Tokyo, Japan). cDNA was obtained via reverse transcription from mRNA according to the instructions of the reverse transcription kit. The expression of miR-19b mRNA was detected by RT-PCR assay, according to the instructions of the RT-PCR kit, and the U6 RNA was used as the internal control. The primer sequences of the miR-19b and U6 are shown in Table I, with the reaction conditions as follows: $95^{\circ} \mathrm{C}$ for $10 \mathrm{~min}, 95^{\circ} \mathrm{C}$ for $15 \mathrm{sec}$ and $60^{\circ} \mathrm{C}$ for $1 \mathrm{~min}$, with a total of 40 cycles of amplification. The $\mathrm{Cq}$ value was calculated by pplied Biosystems 7500 (Applied Biosystems, Foster City, CA, USA) and the relative quantification of gene expression was calculated by the $2-\Delta \mathrm{Cq}$ method, according to the following formula: $\Delta \mathrm{Cq}$ (target gene) $=\mathrm{Cq}$ (target gene) - Cq (control gene).

Western blotting. Cells were seeded in 6-well plates at a density of $1 \times 10^{4}$ cells/well. After $24 \mathrm{~h}$, the supernatant was aspirated and cells were cultured in medium containing 10 , 20 or $40 \mu \mathrm{M}$ naringin for another $24 \mathrm{~h}$. Cells were collected and lysed with cell lysis buffer, then centrifuged for $15 \mathrm{~min}$ at a high speed at $4^{\circ} \mathrm{C}$. After centrifugation, the supernatant was collected. The extracted protein concentrations were determined by a BCA kit. A total of $50 \mu \mathrm{g}$ of protein was separated by SDS-PAGE and the separated protein was transferred to a PVDF membrane. The membrane was incubated in blocking buffer for $1 \mathrm{~h}$ at room temperature and then rabbit monoclonal Bcl-2 antibody (dilution, 1:500; cat. no. ab32124) and rabbit monoclonal Bax antibody (dilution, 1:500; cat. no. ab32503) (both from Abcam, Cambridge, MA, USA) were added and the membrane was incubated overnight at $4^{\circ} \mathrm{C}$. After washing membrane with TTBS, the goat anti-rabbit secondary antibody (dilution, 1:2,000; cat. no. ab6721; Abcam) was added and the membrane was incubated at room temperature for $1 \mathrm{~h}$. ECL was added to the membrane and the blots were developed in the dark, with images recorded using a gel imaging system (Bio-Rad Laboratories, Inc., Hercules, CA, USA). GADPH was used as the internal reference and the gray-scale values were analyzed and compared.

Statistical analysis. Data are presented as means \pm standard deviations and analyzed with SPSS 17.0 (IBM Corp., Armonk, NY, USA), using one-way ANOVA. P<0.05 was considered statistically significant.

\section{Results}

The effect of naringin on HepG2 cell proliferation inhibition. After cells were cultured in the medium containing 10, 20 and $40 \mu \mathrm{M}$ naringin for $24 \mathrm{~h}$, the proliferation of HepG2 cells was significantly inhibited in all groups. The proliferation inhibition rates were significantly increased with the increase of concentration and time $(\mathrm{P}<0.05)$, showing an obvious dose-dependent pattern. The inhibitory rate of proliferation was $53.13 \%$ when $20 \mu \mathrm{M}$ of naringin was used for $24 \mathrm{~h}$ (Table II).

The effects of naringin on Hep 2 cell morphology. To explore possible regulatory mechanisms, 10, 20 and $40 \mu \mathrm{M}$ naringin were chosen as the drug concentrations and incubation time 


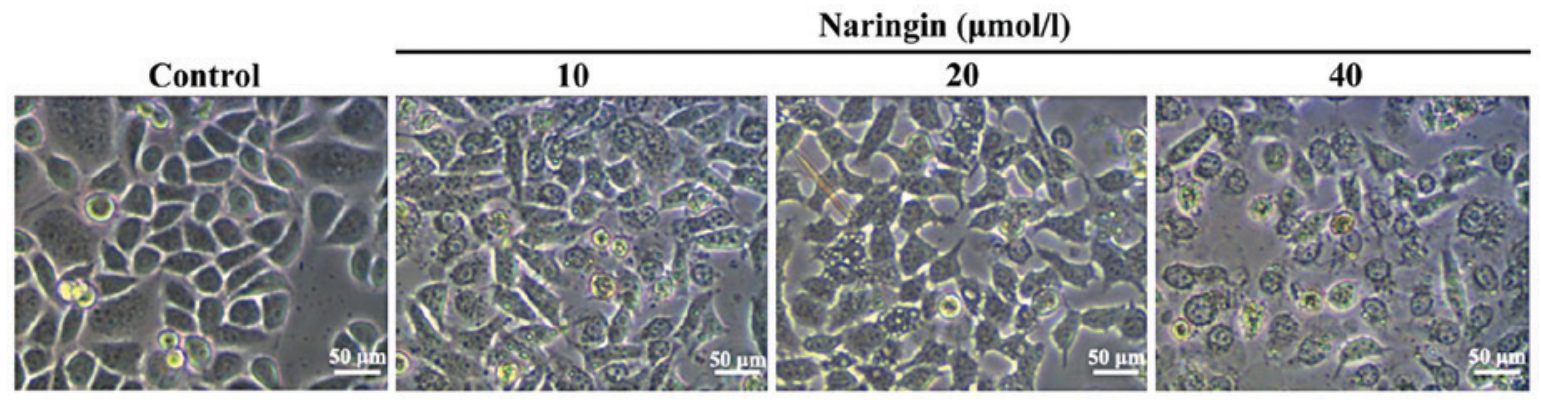

Figure 1. The effects of naringin on morphological changes of HepG2 cells as observed under an inverted microscope after treating cells with different concentrations of naringin for $24 \mathrm{~h}$.

\section{Naringin $(\mu \mathrm{mol} / \mathrm{l})$}
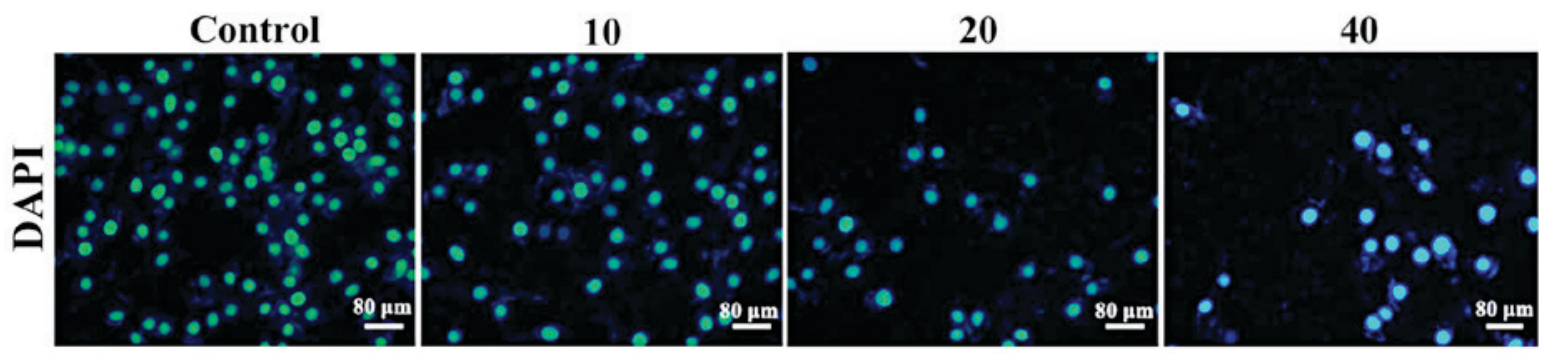

Figure 2. The effects of naringin on HepG2 cell apoptosis as detected by DAPI staining.

Table I. The primer sequences of RT-PCR.

\begin{tabular}{ll}
\hline Gene & \multicolumn{1}{c}{ Primer sequence } \\
\hline miR-19b & F: 5'-UGUGCAAAUCCAUGCAAAACUGA-3' \\
& R: 5'-GCTCACTGCAACCCTCCTCCTCC-3' \\
U6 & F: 5'-GCTTCGGCAGCACATATACTAAAAT-3' \\
& R: 5'-CGCTTCACGAATTTGCGTGTCAT-3'
\end{tabular}

Table II. The effects of different concentrations of naringin on HepG2 cell proliferation inhibition.

\begin{tabular}{lccc}
\hline & \multicolumn{3}{c}{ Cell proliferation inhibition rate $(\%)$} \\
\cline { 2 - 4 } $\begin{array}{l}\text { Concentration } \\
\mu \mathrm{M})\end{array}$ & $24 \mathrm{~h}$ & $48 \mathrm{~h}$ & $72 \mathrm{~h}$ \\
\hline $\begin{array}{l}\text { Control } \\
\text { group (0) }\end{array}$ & 0 & 0 & 0 \\
10 & & & \\
20 & $30.25 \pm 0.12^{\mathrm{a}}$ & $40.32 \pm 4.13^{\mathrm{a}}$ & $45.92 \pm 5.33^{\mathrm{a}}$ \\
40 & $52.13 \pm 0.31^{\mathrm{a}}$ & $62.32 \pm 5.31^{\mathrm{a}}$ & $70.25 \pm 8.12^{\mathrm{a}}$ \\
& $70.67 \pm 1.32^{\mathrm{a}}$ & $80.22 \pm 7.28^{\mathrm{a}}$ & $86.43 \pm 10.21^{\mathrm{a}}$ \\
\hline
\end{tabular}

Data are presented as mean \pm standard deviation among 30 samples. ${ }^{\mathrm{a}} \mathrm{P}<0.01$ vs. the control group.

was $24 \mathrm{~h}$. After cells were cultured for $24 \mathrm{~h}$ with 10,20 and $40 \mu \mathrm{M}$ naringin, compared with the control group, the morphology of the cells had obvious changes, such as cell shrinkage, decreased cell adherence, reduced cell number and

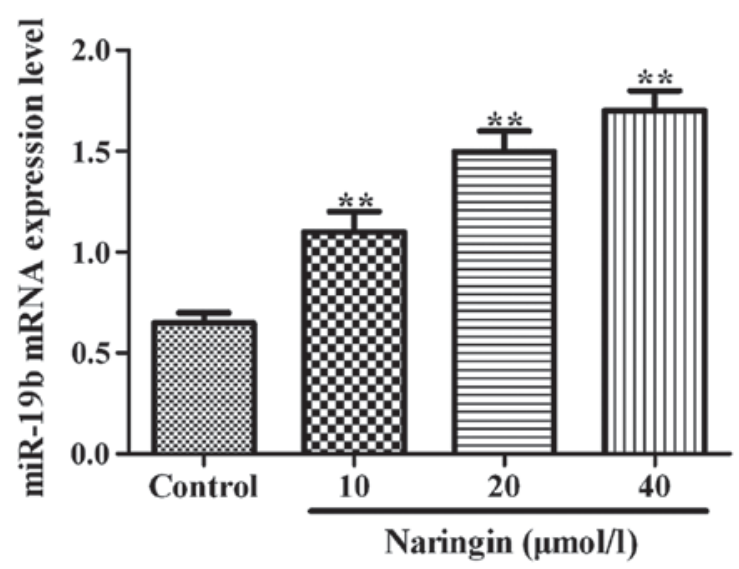

Figure 3. The effects of naringin on the expression levels of miR-19b mRNA in HepG2 cells. Compared with the control group, the expression levels of miR-19b mRNA were significantly increased in naringin treated groups, ${ }^{* *} \mathrm{P}<0.01$.

increased cell death number. These changes of morphology exhibited a notable dose-dependent pattern (Fig. 1).

The effects of naringin on cell apoptosis. After cells were cultured for $24 \mathrm{~h}$ with 10,20 and $40 \mu \mathrm{M}$ naringin, compared with the control group, DAPI staining showed cell shrinkage and nuclear chromatin condensation, suggesting the occurrence of cell apoptosis; moreover, the number of apoptotic cells increased accordingly with an increase in the concentration of naringin (Fig. 2).

The effects of naringin on miR-19b mRNA expression levels. As shown in Fig. 3, compared with the control group, the 
A
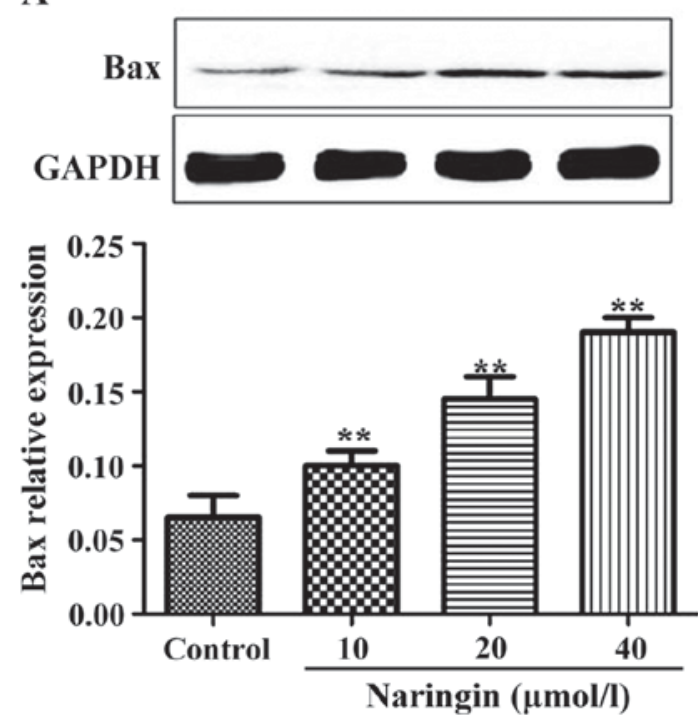

B
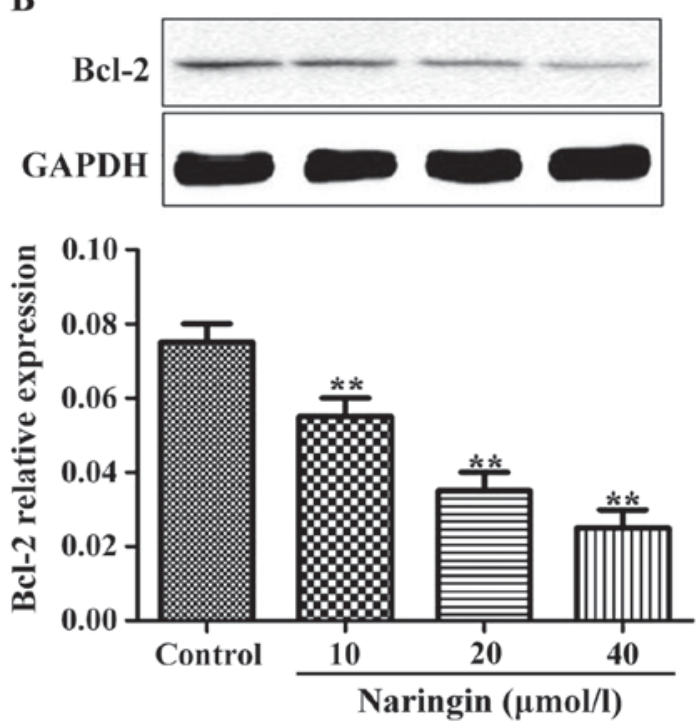

Figure 4. The effects of naringin on the expression levels of Bax and Bcl-2 proteins in HepG2 cells by western blotting. (A) Bax protein expression. (B) Bcl-2 protein expression. Compared with the control group, the expression level of Bax protein was significantly increased and the expression level of Bcl-2 protein was significantly decreased, ${ }^{* *} \mathrm{P}<0.01$.

expression of miR-19b mRNA was significantly increased $(\mathrm{P}<0.01)$ after cells were cultured for $24 \mathrm{~h}$ with 10, 20 and $40 \mu \mathrm{M}$ naringin.

The effects of naringin on Bax and Bcl-2 protein expression levels. After cells were cultured for $24 \mathrm{~h}$ with 10,20 and $40 \mu \mathrm{M}$ naringin, compared with the control group, the expression levels of Bax protein were significantly increased $(\mathrm{P}<0.01)$. The expression levels of Bcl-2 were significantly decreased in the treated groups compared to the control group, showing an inverse dose-dependent pattern to some extent (Fig. 4).

\section{Discussion}

Hepatocellular carcinoma (HCC) is a common malignant tumor and currently has a high mortality rate due to a lack of effective early diagnosis and therapy (11). A variety of factors can lead to the occurrence of liver carcinoma, including chronic liver inflammation caused by excessive drinking, viral hepatitis and non-alcoholic liver fatty degeneration (12).

Traditional Chinese medicine and Chinese herbal medicine are conventional forms of medicine that are unique to China. Traditional Chinese medicine focuses on the overall treatment of the individual and Chinese herbal medicine is characterized by treatments with reduced side effects. Chinese herbal medicine cannot only inhibit the growth of tumor cells, but can also enhance the patient's immune function in the treatment of cancer (13). Natural compounds extracted from Chinese herbal medicines as a novel method for drug discovery, is becoming increasingly accepted and applied in clinical research. This method cannot only obtain compounds with better activity, but can also better control the quality of Chinese herbal medicines. Therefore, the extraction of active chemical ingredients from herbs used in traditional Chinese medicine has become a widely used and promising avenue in antitumor research (14).
Studies have shown that natural products can regulate the proliferation and differentiation of tumor cells by regulating the expression of related miRNAs in tumor cells, thereby inducing tumor cell apoptosis (15). miRNAs are small non-coding RNA molecules that regulate the expression of related genes by specifically binding to the $3^{\prime}$ end untranslated region of the targeted mRNA chain, leading to degradation of the target mRNA or reduction of its stability, thereby regulating the gene transcription and expression (10). Different miRNAs have been found to be differentially expressed in many tumor cells; moreover, further studies have shown that abnormal expressions of miRNAs play key roles in the proliferation, differentiation and apoptosis of tumor cells (16).

It has been found that miR-19b is highly expressed in bladder carcinoma, vesicular rhabdomyosarcoma and colon cancer, and its high expression is closely related to tumor angiogenesis, disease prognosis and survival rate (17-19). Another study reported that miR-19b expression in prostate and cervical cancers has a role in promoting tumorigenesis (20). However, miR-19 could inhibit the proliferation, invasion and metastasis of hepatocellular carcinoma (21).

$\mathrm{Bcl}-2$ is an apoptosis inhibitory protein and plays a key role in the signaling pathway of apoptosis. It protects cells from apoptosis induced by many factors and increases the proliferation and viability of cells. When $\mathrm{Bcl}-2$ protein expression is upregulated, the apoptosis rate of tumor cells decreases significantly, suggesting that $\mathrm{Bcl}-2$ protein and apoptosis of tumor cells have a very close relationship (22). The effects of Bax protein on apoptosis are contrary to $\mathrm{Bcl}-2$, as it functions as a pro-apoptotic protein. Bax and Bcl-2 genes belong to the same gene family and Bax can both antagonize the inhibitory effect of Bcl-2 on cell apoptosis as well as act directly on the cells to promote tumor cell apoptosis (23). Studies have shown that, when Bcl-2 exists as a homodimer, it acts to inhibit apoptosis. In contrast, when Bax exists as a homodimer or polymerizes with Bcl-2 into a dimer, it plays a role in promoting apoptosis (24). 
In the present study, the hepatocellular carcinoma cell line, HepG2, was treated with different concentrations of naringin and then observed at progressive time points of 24, 48 and $72 \mathrm{~h}$. The results of the MTT assay showed that naringin significantly inhibited the proliferation of HepG2 cells compared with the control group. Notable morphological changes of apoptotic HepG2 cells after treatment with naringin were found under inverted microscope. The results of DAPI staining showed cell shrinkage and nuclear chromatin condensation. The results of RT-PCR showed that naringin could upregulate the expression of miR-19b mRNA. Comparable studies have demonstrated that the expression of miRNA-19b was significantly increased after HepG2 cells were treated with total alkaloid extracts of Rhizoma Corydalis, another herb from Chinese herbal medicine. These results support the theory that the expression of miRNA-19b may be an important mechanism against tumorigenesis $(25,26)$.

Western blotting showed an increase in the expression of Bax protein and a decrease in the expression of $\mathrm{Bcl}-2$ protein with an increase in naringin concentration. This implies that naringin could upregulate Bax and downregulate Bcl-2 protein expression, thereby inducing cell apoptosis. $\mathrm{Xi}$ et al (27), indicated that carnosol increased Bax expression and decreased Bcl-2 protein expression by $34-53 \%$ in leukemic cells. Although carnasol is derived from a different botanical source, its mechanism of action is comparable to that of naringin. Collectively, the existing evidence supports a theoretical framework for the therapeutic effects of naringin against liver carcinoma. However, the required therapeutic drug concentrations and efficacy in vivo need to be further explored with animal experiments and clinical trials.

In conclusion, the results of this study demonstrate that naringin can inhibit the proliferation of hepatocellular carcinoma HepG2 cell lines and induce apoptosis. The induction of apoptosis may be achieved by upregulating the expression of miRNA-19b mRNA and Bax protein and downregulating the expression of Bcl-2 protein. Through these mechanisms, naringin has potential as an effective medicinal therapy against liver carcinoma in clinical applications.

\section{References}

1. Parkin DM, Bray F, Ferlay J and Pisani P: Global cancer statistics, 2002. CA Cancer J Clin 55: 74-108, 2005.

2. Jemal A, Bray F, Center MM, Ferlay J, Ward E and Forman D: Global cancer statistics. CA Cancer J Clin 61: 69-90, 2011.

3. Ma LW and Jia TZ: Optimal management for hepatocellular carcinoma. China J Cancer Prev Treat 12: 471-473, 2005.

4. Kettenbach J, Stadler A, Katzler IV, Schernthaner R, Blum M, Lammer J and Rand T: Drug-loaded microspheres for the treatment of liver cancer: review of current results. Cardiovasc Intervent Radiol 31: 468-476, 2008.

5. Kanno S, Shouji A, Asou K and Ishikawa M: Effects of naringin on hydrogen peroxide-induced cytotoxicity and apoptosis in P388 cells. J Pharmacol Sci 92: 166-170, 2003.
6. Birt DF, Hendrich S and Wang W: Dietary agents in cancer prevention: Flavonoids and isoflavonoids. Pharmacol Ther 90: 157-177, 2001.

7. Bartel DP: MicroRNAs: Genomics, biogenesis, mechanism, and function. Cell 116: 281-297, 2004.

8. Mendell JT: miRiad roles for the miR-17-92 cluster in development and disease. Cell 133: 217-222, 2008.

9. Jung YJ, Kim JW, Park SJ, Min BY, Jang ES, Kim NY, Jeong SH, Shin CM, Lee SH, Park YS, et al: c-Myc-mediated overexpression of miR-17-92 suppresses replication of hepatitis B virus in human hepatoma cells. J Med Virol 85: 969-978, 2013.

10. Liu M, Wang Z, Yang S, Zhang W, He S, Hu C, Zhu H, Quan L, Bai J and Xu N: TNF- $\alpha$ is a novel target of miR-19a. Int $J$ Oncol 38: 1013-1022, 2011.

11. Tang W, Zhu J, Su S, Wu W, Liu Q, Su F and Yu F: MiR-27 as a prognostic marker for breast cancer progression and patient survival. PLoS One 7: e51702, 2012

12. Nakagawa H, Umemura A, Taniguchi K, Font-Burgada J, Dhar D, Ogata H, Zhong Z, Valasek MA, Seki E, Hidalgo J, et al: ER stress cooperates with hypernutrition to trigger TNF-dependent spontaneous HCC development. Cancer Cell 26: 331-343, 2014.

13. Hwang HW and Mendell JT: MicroRNAs in cell proliferation, cell death, and tumorigenesis. Br J Cancer 96 (Suppl): R40-R44, 2007.

14. le Sage $C$ and Agami R: Immense promises for tiny molecules: Uncovering miRNA functions. Cell Cycle 5: 1415-1421, 2006.

15. Kusenda B, Mraz M, Mayer J and Pospisilova S: MicroRNA biogenesis, functionality and cancer relevance. Biomed Pap Med Fac Univ Palacky Olomouc Czech Repub 150: 205-215, 2006.

16. Xu SP, Sun GP, Shen YX, Wei W, Peng WR and Wang H: Antiproliferation and apoptosis induction of paeonol in HepG2 cells. World J Gastroenterol 13: 250-256, 2007.

17. Ayala de la Peña F, Kanasaki K, Kanasaki M, Tangirala N, Maeda $\mathrm{G}$ and Kalluri R: Loss of p53 and acquisition of angiogenic microRNA profile are insufficient to facilitate progression of bladder urothelial carcinoma in situ to invasive carcinoma. J Biol Chem 286: 20778-20787, 2011.

18. Reichek JL, Duan F, Smith LM, Gustafson DM, O'Connor RS, Zhang C, Dunlevy MJ, Gastier-Foster JM and Barr FG: Genomic and clinical analysis of amplification of the $13 \mathrm{q} 31$ chromosomal region in alveolar rhabdomyosarcoma: A report from the Children's Oncology Group. Clin Cancer Res 17: 1463-1473, 2011.

19. Wang YX, Lang F, Liu YX, Yang CQ and Gao HJ: In situ hybridization analysis of the expression of miR-106b in colonic cancer. Int J Clin Exp Pathol 8: 786-792, 2015.

20. Tian L, Fang YX, Xue JL and Chen JZ: Four microRNAs promote prostate cell proliferation with regulation of PTEN and its downstream signals in vitro. PLoS One 8: e75885, 2013.

21. Xu XM, Wang XB, Chen MM, Liu T, Li YX, Jia WH, Liu M, Li X and Tang H: MicroRNA-19a and $-19 b$ regulate cervical carcinoma cell proliferation and invasion by targeting CUL5. Cancer Lett 322: 148-158, 2012.

22. Packham G and Cleveland JL: c-Myc and apoptosis. Biochimica et Biophysica Acta 1242: 11-28, 1995.

23. Brady HJ and Gil-Gómez G: Bax. The pro-apoptotic Bcl-2 family member, Bax. Int J Biochem Cell Biol 30: 647-650, 1998.

24. Lu QL, Abel P, Foster CS and Lalani EN: bcl-2: Role in epithelial differentiation and oncogenesis. Hum Pathol 27: 102-110, 1996.

25. Bae S, Lee EM, Cha HJ, Kim K, Yoon Y, Lee H, Kim J, Kim YJ, Lee HG, Jeung HK, et al: Resveratrol alters microRNA expression profiles in A549 human non-small cell lung cancer cells. Mol Cells 32: 243-249, 2011.

26. Law PT and Wong N: Emerging roles of microRNA in the intracellular signaling networks of hepatocellular carcinoma. J Gastroenterol Hepatol 26: 437-449, 2011.

27. Xi S, Dyer KF, Kimak M, Zhang Q, Gooding WE, Chaillet JR, Chai RL, Ferrell RE, Zamboni B, Hunt J, et al: Decreased STAT1 expression by promoter methylation in squamous cell carcinogenesis. J Natl Cancer Inst 98: 181-189, 2006. 